\section{JTI}

JOURNAL OF

TRAUMA AND INJURY
Received: September 24, 2020

Accepted: September 24, 2020

\section{Correspondence to}

Gil Jae Lee, M.D., Ph.D.

Department of Traumatology, Gachon University College of Medicine, 783

Namdong-daero, Namdong-gu, Incheon 21556, Korea

Tel: $+82-32-460-3010$

Fax: $+82-32-460-2372$

E-mail: nonajugi@gilhospital.com

\title{
To Celebrate the Publication of a Special Topic for REBOA
}

\author{
Min A Lee, M.D., Gil Jae Lee, M.D., Ph.D. \\ Department of Traumatology, Gachon University College of Medicine, Incheon, Korea
}

Journal of Trauma and Injury (JTI) covers a wide range of trauma topics and is made up of a variety of specialists. JTI has been designated as an index journal of the national research foundation of Korea 2 years ago. We are constantly striving to be selected as an international academic journal in the future.

In this September issue, we have prepared a special topic for resuscitating intravascular balloon occlusion of the aorta (REBOA). REBOA has been known effective in controlling torso hemorrhage and less invasive than resuscitative thoracotomy [1]. Many trauma centers have already been using REBOA as a bridge tool for patients with severe bleeding. In Korea, 7 Fr sized sheath has been introduced since 2018, making it easier to perform REBOA procedures.

This special topic consisted of one review article, three original articles, and five case report studies. The review article is about 'Educational Simulation Videos for Performing Resuscitative Endovascular Balloon Occlusion of the Aorta', and the video file is attached, so it may be helpful to those who are new to REBOA. In addition, there is an original article about the multicenter study on the early experiences of REBOA in Korea. And various topics on REBOA such as pitfalls, complications, and application to children and neurotrauma are introduced.

We hope this special topic will help readers manage trauma patients, and your various experiences will lead to a lot of research in the future. May the dangers of COVID-19 disappear as soon as possible. Thank you.

\section{REFERENCE}

1. Long B, Hafen L, Koyfman A, Gottlieb M. Resuscitative endovascular balloon occlusion of the aorta: a review for emergency clinicians. J Emerg Med 2019;56:687-97. (http://creativecommons.org/licenses/by-nc/4.0/) which permits unrestricted noncommercial use, distribution, and reproduction in any medium, provided the original work is properly cited. 